\title{
Fernreisen
}

\section{Welche Impfungen jetzt wichtig sind}

Häufige, impfpräventable Infektionen auf Reisen sind Influenza und Typhus. Auch wird Brasilien-Reisenden aktuell eine Gelbfieber-Impfung empfohlen: Das Land kämpft mit dem schlimmsten Ausbruch seit 30 Jahren.

Anfang des Jahres meldete die WHO einen Gelbfieber-Ausbruch in Brasilien, der sich mittlerweile mit 3240 Verdachtsfällen und 435 Todesfällen zum größten Gelbfieber-Ausbruch in Brasilien seit 30 Jahren entwickelt hat. Das Centrum für Reisemedizin (CRM) rät daher ausnahmslos allen Brasilien-Reisenden, sich gegen Gelbfieber impfen zu lassen. Auch in Nachbarländern von Brasilien habe es Gelbfieber-Fälle gegeben, bemerkte Prof. Tomas Jelinek, Wissenschaftlicher Leiter des CRM, bei einer Veranstaltung in Berlin.

Erst 2014 hatte die Weltgesundheitsorganisation WHO Daten vorgestellt, wonach eine einmalige Gelbfieber-Impfung für einen lebenslangen Schutz ausreicht. Daraufhin wurden auch in Deutschland die STIKO-Empfehlungen diesbezüglich geändert.

Am wichtigsten für die Reisemedizin sei weiterhin das Dengue-Fieber, so Jelinek. „Keine Tropenkrankheit kommt von der Zahl der Erkrankungen auch nur ansatzweise an das Dengue-Fieber heran. In den Tropen und Subtropen ist kein einziges Land frei von Dengue-Fällen." Die Überträgermücke Aedes aegypti sei aber auch in Südeuropa nachgewiesen worden, etwa in Frankreich und Italien. „Glücklicherweise verläuft die Krankheit aber nur selten tödlich", sagte Jelinek.

\section{Zulassung einer ersten Vakzine}

Die intensive Forschung an einem Impfstoff gegen Dengue habe zur Zulassung einer ersten Vakzine in einzelnen Endemieländern geführt. „Die protektive Effektivität liegt bei immunologisch Naiven nur bei rund 20\%", sagte Jelinek. Schutz vor einer Infektion mit den Dengue-Virus bietet daher das Vermeiden von Stichen der tagaktiven Aedes-Mücke mit langer Kleidung, Repellents und Moskitonetzen. Eine weitere für die Reisemedizin wichtige Impfung ist die Typhus-Impfung, gera-

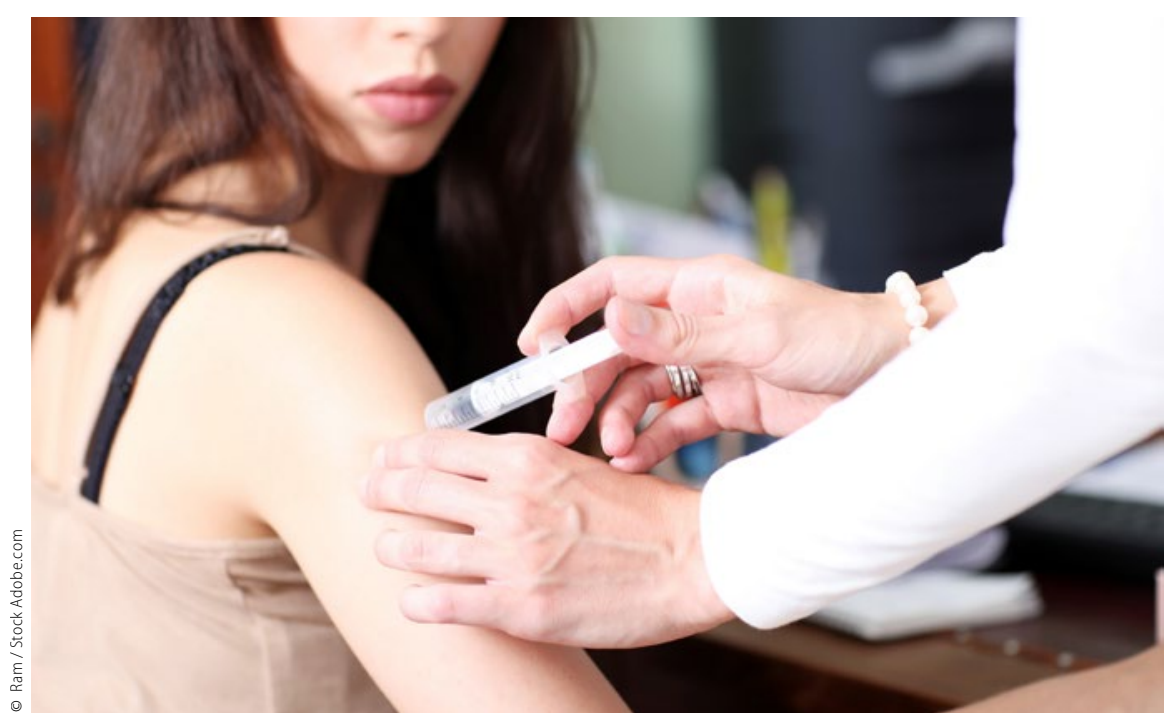

Vor Fernreisen sollten in jedem Fall der Basis-Impfschutz überprüft und Impflücken geschlossen werden.

de für Reisende in südostasiatische Länder. Das CRM gibt für den Impferfolg der Schutzimpfung eine Schutzrate von 50$70 \%$ an. Es gebe zudem eine Kombinationsimpfung gegen Typhus und Hepatitis A, die allerdings zur Zeit in Deutschland nicht verfügbar sei.

\section{Auf Basisimpfschutz achten!}

Schließlich riet Jelinek zur Impfung gegen Tollwut. „Tollwut muss man in der reisemedizinischen Beratung für fast alle Reiseländer dieser Welt ansprechen." Relevant sei Rabies etwa auf Bali, wo es seit 2008 einen laufenden Ausbruch gebe, der von den Behörden bisher nicht in den Griff zu kriegen ist. „Indien ist neben Bangladesch das Land mit der höchsten Inzidenz, Fälle werden aber auch gehäuft aus Nordafrika gemeldet", so Jelinek.

Da Reisende meist Erwachsene sind, die sonst nur selten zum Arzt gehen, sollte bei einer reisemedizinischen Beratung grundsätzlich der Basis-Impfschutz überprüft werden. Zeigen sich Impflücken, etwa gegen Masern, Polio, Diphtherie, Tetanus oder Pertussis, ist es wichtig, die jeweiligen Impfungen durchzuführen.

Gerade die Masern-Impfung ist auch auf Reisen sinnvoll, da die Erkrankungszahlen in vielen Ländern zunehmen. So wurden seit Anfang des Jahres in Italien rund 3075 Infektionen gemeldet.

Bisher wurden in Deutschland nach Angaben des CRM 826 Erkrankungen gemeldet, im vergangenen Jahr waren es insgesamt 323. Eine 37-jährige Frau aus Essen starb vor wenigen Wochen an den Folgen einer Masern-Infektion.

Auch außerhalb der hiesigen Saison kann für Personen, die eine Fernreise planen, eine Influenza-Impfung sinnvoll sein, so das CRM. Dies gilt besonders bei Aufenthalten auf Kreuzfahrtschiffen oder bei Ausflügen innerhalb einer größeren Reisegruppe. Vor allem sollten sich alle über 60-Jährigen und chronisch Kranke vor Reiseantritt gegen Grippe impfen lassen. 